Jurnal Keperawatan Muhammadiyah

Alamat Website: http://journal.um-surabaya.ac.id/index.php/JKM

\title{
Optimalisasi Program Continuing Professional Development (CPD) Untuk Mendukung Peningkatan Kompetensi dan Karir Perawat RSI Surabaya
}

\author{
Muhadi ${ }^{1}$,Titin Wahyuni ${ }^{2}$
}

${ }^{1,2}$ STIKES Yayasan RS. Dr. Soetomo Surabaya

\section{INFORMASI}

Korespondensi:

lono@unusa.ac.id

\section{ABSTRACT}

The purpose of this study was to map the level of participation, driving and inhibiting factors for the implementation of the Continuing Professional Development (CPD) program.

This study used a cross-sectional study design with a quantitative descriptive approach. The study population was all RSI nurses with a total sample of 104 survey participants with purposive sampling technique. Data were collected using an online questionnaire through the google form application from June to September 2020. Data analysis was carried out through SPPS 17 and presented in descriptive and tabulated narrative.

The results of the study were the level of participation of nurses at the Surabaya Is-

Keywords:

Understanding The Meaning Of Life, Health Perspective, Elderly lamic Hospital in carrying out CPD activities which were divided into 3 categories, namely high, medium and low participation. A total of (17.3\%) belonged to the low level of participation, (69.2\%) the level of participation was medium and (13.5\%) was classified as high. Some of the nurses in this survey reported reaching structural and clinical positions of nurses quickly through the skills, approaches and recommendations of managers. Short-term development plans are a priority for nurses' thinking in improving (CPD), namely the continuous fulfillment of complete nursing care practices and increasing the clinical career level.

The long-term development plan for nurses is that some want to continue educational programs at a higher level such as specialized education and master's degree in nursing. 


\section{PENDAHULUAN}

Kemampuan perawat dalam pengembangan diri melibatkan pengetahuan dan keterampilan. Pengembangan kemampuan perlu mencakup dukungan pembelajaran bagi perawat untuk memajukan karir mereka dan memiliki kesempatan untuk mengembangkan pengetahuan dan keterampilan baru untuk melakukan berbagai peran di rumah sakit. Pengembangan profesional mengacu pada keterampilan dan pengetahuan yang diperoleh untuk kemajuan pribadi (Department of Health South Australian, 2014). Pengembangan praktik keperawatan dilakukan melalui pendidikan formal dan pendidikan nonformal atau pendidikan berkelanjutan. Pengembangan Praktik Keperawatan bertujuan untuk mempertahankan atau meningkatkan keprofesionalan perawat (Kementrian Kesehatan RI, 2014).

Karier keperawatan dapat bertahan selama lebih dari 40 tahun, di mana kelanjutan pengembangan profesional sangat penting. Perawat berpartisipasi dalam berbagai kegiatan pembelajaran yang sesuai dengan motif perkembangan mereka. Psikologi umur menunjukkan bahwa motif yang terkait dengan pekerjaan berubah seiring usia, yang mengarah pada harapan bahwa motif untuk melanjutkan pengembangan profesional juga berubah. Namun demikian, sedikit yang diketahui tentang strategi pengembangan profesional berkelanjutan perawat dalam kelompok usia yang berbeda. (Pool, Poell, Berings, \& Ten Cate, 2015).

Perawat merupakan bagian integral dalam perawatan pasien dan memainkan peran penting dalam meningkatkan kualitas di rumah sakit. Perawat memiliki tanggung jawab untuk memastikan keselamatan pasien dengan kompetensi yang memadai, dan ketersediaan program yang dapat mengoptimalkan kompetensi perawat adalah upaya penting dalam membantu perawat dalam memberikan perawatan yang kompeten dan aman. Kompetensi perawat harus dipertahankan melalui pengembangan profesional berkelanjutan (Hariyati, Igarashi, Fujinami, Susilaningsih, \& Prayenti, 2017). Sebagian besar belum mencapai target pelatihan perawat < 30 Jam Per Tahun di RSI Ahmad Yani Surabaya Tahun 2018(Rumah Sakit Islam Surabaya, 2018). Berdasarkan laporan penelitian analisis kebutuhan pelatihan perawat RSI diperoleh hasil umur dan masa kerja perawat masih tergolong muda dengan tingkat pendidikan terbanyak adalah diploma 3 keperawatan. Berdasarkan data yang diperoleh, maka dapat dirumuskan permasalahan yaitu Pertama, pengembangan kompetensi perawat melalui pelatihan belum sesuai target. Kedua, sebagain besar perawat tergolong muda dan kurang pengalaman (Muhadi, 2019) Berdasarkan fenoma permasalahan tersebut maka penelitian ini bertujuan adalah untuk memetakan tingkat partisipasi, faktor pendorong dan penghambat pelaksanaan program Continuing Professional Development (CPD).

\section{METODE}

Jenis penelitian ini termasuk jenis penelitian deksriptif kuantitatif dengan bentuk rancangan penelitian cross sectional, untuk mengkaji tingkat partisipasi, kesadaran perawat untuk melaksanakan CPD di RSI Surabaya. Populasi dalam penelitian ini adalah seluruh perawat RSI Surabaya. Teknik pengambilan sampel dalam penelitian ini dilakukan dengan teknik purposing sampling yaitu perawat yang terdistribusi di bagian rawat jalan, rawat inap, gawat darurat, ruang khusus dan hemodialisa sebanyak 104 perawat. Pengambilan data dilakukan dengan model survei melalui kuesioner online dengan menggunakan aplikasi google form. Tingkat partisipasi diukur skala likert penilaian yaitu 1 (tidak pernah) sampai dengan 5 (sering atau selalu). Analisis data dilakukan melalui SPPS 17 dan disajikan secara narasi deskriptif dan tabulasi.

\section{HASIL}

Tabel 1 menggambarkan profile perawat Rumah Sakit Islam Surabaya sebanyak 104 responden menunjukkan bahwa mayoritas peserta yang berpartisipasi dalam survei ini adalah usia muda atau generasi $\mathrm{Y}$ yaitu (59.6\%) termuda berusia $22-30$ tahun, perempuan (83.7\%), sudah menikah (70.2\%). Pendidikan perawat mayoritas dari ners $(51.9 \%)$ dan diikuti pendidikan diploma perawat (47.1\%). Masa kerja tergolong muda yaitu (43.3\%) yaitu antara 1-3 tahun. Sebagai besar partisipan survei berasal dari unit rawat inap sebesar (70.2\%). Berdasarakan jenjang karir perawat sebagian besar partisipan memiliki jenjang level 1 sebagai perawat klinis rumah sakit (56.6\%). Perawat yang menduduki posisi sebagai staff yaitu (96.5\%) dan struktural sebesar (13.5\%). 
Tabel 1. Profile Perawat RSI Surabaya

\begin{tabular}{|c|c|c|}
\hline Karakteristik Individu & f & $\%$ \\
\hline \multicolumn{3}{|l|}{ Umur } \\
\hline 22-30 Tahun & 62 & 59.6 \\
\hline 31-40 Tahun & 17 & 16.3 \\
\hline$>40$ Tahun & 25 & 24.1 \\
\hline \multicolumn{3}{|l|}{ Jenis Kelamin } \\
\hline Perempuan & 87 & 83.7 \\
\hline Laki-Laki & 17 & 18.3 \\
\hline \multicolumn{3}{|l|}{ Status Pernikahan } \\
\hline Sudah Menikah & 73 & 70.2 \\
\hline Belum Menikah & 31 & 29.8 \\
\hline \multicolumn{3}{|l|}{ Status Kepegawaian } \\
\hline Tenaga Tetap & 60 & 57.7 \\
\hline Tenaga Kontrak & 44 & 42.3 \\
\hline \multicolumn{3}{|l|}{ Pendidikan } \\
\hline Diploma & 49 & 47.1 \\
\hline Ners & 51 & 51.9 \\
\hline Magister & 1 & 1 \\
\hline \multicolumn{3}{|l|}{ Masa Kerja } \\
\hline 1-3 Tahun & 45 & 43.3 \\
\hline 3,1-5 Tahun & 20 & 19.2 \\
\hline 5,1-10 Tahun & 8 & 7.7 \\
\hline$>10$ Tahun & 31 & 29.8 \\
\hline \multicolumn{3}{|l|}{ Unit Kerja } \\
\hline IGD & 14 & 13.5 \\
\hline Rawat Inap & 73 & 70.2 \\
\hline Rawat Jalan & 8 & 7.7 \\
\hline Ruang Khusus (ICU,NICU) & 5 & 4.8 \\
\hline Hemodialisa & 4 & 3.8 \\
\hline
\end{tabular}

Jenjang Karir

Perawat Klinis 1

$37 \quad 56.6$

Perawat Klinis 2

$35 \quad 37.7$

Perawat Klinis 3

$31 \quad 29.8$

Perawat Klinis 4

$1 \quad 1$

Jabatan

$\begin{array}{lll}\text { Staff } & 90 & 86.5 \\ \text { Struktural } & 14 & 13.5\end{array}$

Penelitian ini melibatkan 104 partisipan yaitu mengukur tingkat partisipasi CPD Perawat Rumah Sakit Islam Surabaya dengan menggunakan 18 indikator kegiatan dengan skala pengukuran 1 sampai 5 mulai dari yang tidak pernah sampai yang sering melakukannya. Tingkat partisipasi perawat menunjukkan hasil kegiatan terbanyak skala 5 yaitu sering bekerja dengan mentor dan praktik klinis yang diawasi oleh kepala ruangan. Tingkat partisipasi perawat menunjukkan hasil kegiatan terbanyak skala 4 (kadang dilakukan) yaitu membaca buku keperawatan, menyelesaikan secara tuntas buku bacaan, partisipasi dalam kegiatan focus group discuss, partisipasi dalam kegiatan audit klinis perawat, membaca jurnal atau artikel keperawatan, menonton video tutorial terkait praktik asuhan keperawata di youtube, membimbing mahasiswa praktik atau magang, melakukan evaluasi kinerja individu dan memiliki catatan harian (logbook). Tingkat partisipasi perawat pada skala 3 (jarang dilakukan) yaitu berkontribusi dalam research keperawatan, Menghadiri seminar sehari keperawatan, terlibat aktif kegiatan organisasi perawat (PPNI), berpartisipasi dalam kegiatan akreditasi rumah sakit, berpartisipasi dalam kegiatan penyusunan pedoman dan kebijakan terkait perawat. Tingkat partisipasi perawat pada skala 1 (tidak pernah dilakukan) yaitu menulis artikel terkait keperawatan di media online, mengikuti kegiatan bimbingan teknis keperawatan. Tabel 2 menggambarkan tingkat partisipasi perawat Rumah Sakit Islam Surabaya dalam melaksanakan kegiatan CPD yang terbagi dalam 3 kategori yaitu partisipasi tinggi, sedang dan rendah. Sebanyak (17.3\%) tergolong kedalam tingkat partisipasi rendah, (69.2\%) tingkat partisipasi sedang dan (13.5\%) tergolong tinggi.

\section{Tabel 2. Tingkat Partisipasi CPD Perawat RSI}

\begin{tabular}{lcc}
\hline Tingkat Partisipasi Program & f & \% \\
\hline Rendah & 18 & 17.3 \\
Sedang & 72 & 69.2 \\
Tinggi & 14 & 13.5 \\
\hline & 104 & 100
\end{tabular}

Tabel 3 menggambarkan Faktor Pendukung dan Penghambat implementasi CPD perawat yang terdiri dari dukungan kebijakan rumah sakit, dukungan pembiayaan, feedback, personal feedback dan kualitas kerja. Faktor dukungan kebijakan pengembangan diukur menggunakan 8 kriteria yaitu kebijakan jenjang karir, ijin cuti mengikuti pendidikan dan pelatihan, inhouse dan outhouse training, sarana dan prasarana yang memadai, jaringan internet dan akses informasi yang selalu tersedia. Partisipan hampir seluruhnya menjawab tersedia (91.3\%). Faktor dukungan pembiayaan diukur menggunakan 8 kriteria yaitu pendanaan yang bersumber dari pribadi, hibah pemerintah dan swasta, keluarga, orangtua, rumah sakit, organisasi profesi. Partisipan hampir seluruhnya menjawab dukungan rendah (88.5\%). Faktor dukungan feedback diukur menggunakan 8 kriteria yaitu akses pengembangan profesi, rapat kelompok supervisi klinis, rapat internal, tinjauan 
sejawat, tim ad hoc dan penilaian kebutuhan klinis. Partisipan sebagain besar menjawab tersedia dukungan feedback kegiatan klinis (80.8\%). Faktor dukungan personal feedback diukur menggunakan 8 kriteria yaitu direktur, sejawat, kepala ruangan, asessor, supervisi unit, pasien dan keluarga pasien, komite keperawatan dan staf medis. Partisipan sebagain besar menjawab tersedia dukungan personal feedback (78.8\%). Faktor dukungan kualitas kerja diukur menggunakan 5 kriteria yaitu faktor kenyamanan kerja, kepuasan, waktu luang, rasa bosan, kedisiplinan dan penghargaan. Partisipan sebagain menjawab kualitas kerja tinggi (50\%). Faktor kondisi oragnisasi diukur menggunakan 8 kriteria yaitu gaya kepemimpinan, desentralisasi kerja, promosi, kesempatan karir, modul keperawatan, orientasi, kebutuhan layanan pasien. Partisipan sebagain menjawab kondisi kerja sangat kondusif (78.8\%). Faktor penghambatan diukur menggunakan 4 kriteria yaitu diri sendiri, keluarga, rumah sakit dan lingkungan. Sebagian besar perawat menjawab tergologn rendah $(83.7 \%)$.

Tabel 3. Faktor Pendukung dan Penghambat CPD Perawat RSI

\begin{tabular}{lcccc}
\hline \multicolumn{1}{c}{ Faktor Pendukung } & $\mathbf{f}$ & $\%$ & Mean & SD \\
\hline Dukungan Kebijakan & & & & \\
$\quad$ Tinggi & 95 & 91.3 & 1.9 & .55 \\
$\quad$ Rendah & 9 & 8.7 & & \\
\hline Dukungan Pembiayaan & & & & \\
$\quad$ Tinggi & 12 & 11.5 & 2.4 & .52 \\
$\quad$ Rendah & 92 & 88.5 & & \\
\hline Feedback & & & & \\
$\quad$ Tinggi & 84 & 80.8 & 1.9 & .54 \\
$\quad$ Rendah & 20 & 19.2 & & \\
\hline Personal Feedback & & & & \\
$\quad$ Tinggi & 82 & 78.8 & 2.1 & .55 \\
$\quad$ Rendah & 22 & 21.2 & & \\
\hline Kualitas Kerja & & & & \\
$\quad$ Tinggi & 51 & 49 & & \\
$\quad$ Sedang & 52 & 50 & 2.0 & .51 \\
$\quad$ Rendah & 1 & 1 & & \\
\hline Kondisi Kerja & & & & \\
$\quad$ Sangat Kondusif & 82 & 78.8 & & \\
$\quad$ Kondusif & 15 & 14.4 & 2.3 & .58 \\
$\quad$ Kurang Kondusif & 7 & 6.7 & & \\
\hline Faktor Penghambat & & & & \\
$\quad$ Tinggi & 17 & 16.3 & 2.1 & .60 \\
$\quad$ Rendah & 87 & 83.7 & & \\
\hline Rencana pengem & &
\end{tabular}

Rencana pengembangan individu adalah suatu perencanaan tentang mada depan yang ingin dicapai seorang perawat meniti proses perbaikan kualitas diri dan kenaikan pangkat atau pendidikan sesuai persyaratan dan kemampuannya. Rencana pengembangan individu di ukur menggunakan 2 dimensi yaitu dimensi rencana jangka pendek dan rencana jangka panjang. Rencana jangka pendek di ukur dengan rentan waktu kurang dari 1 tahun sedangkan rencana pengembangan jangka panjang kurun waktu lebih dari 1 tahun. Rencana pengembangan diri jangka pendek perawat rumah sakit Islam Surabaya hampir seluruhnya (> 90\%) menjawab pemenuhan asuha keperawatan secara berkesinambungan dan peningkatan jenjang karir sedangkan rencana jangka panjang pengembangan diri perawat $(29.8 \%)$ tidak memiliki rencana jangka panjang dan $(14.4 \%)$ ingin melanjutkan pendidikan ke jenajng sarjana atau profesi ners. Dibawah $(<5 \%)$ ingin melanjutkan pendidikan ditingkat magister, doktor dan spesialisasi (Ns.Sp).

Tabel 4. Rencana Pengembangan Individu Perawat RSI

\begin{tabular}{|c|c|c|}
\hline Rencana Jangka Pendek & f & $\%$ \\
\hline $\begin{array}{l}\text { engan pimpinan terkait area } \\
\text { s }\end{array}$ & 89 & 85.6 \\
\hline $\begin{array}{l}\text { Konsultasi layanan kebutuhan pasien } \\
\text { dan rumah sakit }\end{array}$ & 75 & 72.1 \\
\hline han keperawatan secara & 102 & 98.1 \\
\hline & 99 & 95.2 \\
\hline $\begin{array}{l}\text { Meningkatkan Jenja } \\
\text { Meningkatkan Peng }\end{array}$ & 71 & 68.3 \\
\hline $\begin{array}{l}\text { Membuat Program Peningkatan kapasi- } \\
\text { tas mandiri }\end{array}$ & 78 & 75 \\
\hline Rencana Jangka Panjang & $\mathrm{f}$ & $\%$ \\
\hline $\begin{array}{l}\text { Tidak Memiliki Rencana Jangka Pan- } \\
\text { jang }\end{array}$ & 31 & 29.8 \\
\hline & 1 & 14.4 \\
\hline $\begin{array}{l}\text { Melanjutkan Pendidikan Jenjang Spesi- } \\
\text { alis }\end{array}$ & & 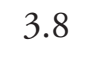 \\
\hline & 5 & 4.8 \\
\hline & 1 & \\
\hline Pelat & 4 & 3.8 \\
\hline
\end{tabular}

\section{PEMBAHASAN}

Penelitian ini menyelidiki profil perawat, tingkat partisipasi CPD perawat, dan faktor pendukung dan penghambat implementasi CPD perawat di rumah sakit. Hal ini juga memastikan apakah ada pengaruh yang signifikan dalam tingkat partisipasi perawat terhadap faktor pendukung dan penghambat CPD perawat. Studi ini juga berusaha untuk mengidentifikasi rencana pengembangan diri perawat jangka pendek maupun jangka panjang. Profil kerja 
perawat berkaitan dengan identitias diri atau ciri khas yang menggambarkan identitas pekerjaan seorang perawat di rumah sakit Islam Surabaya.

Faktor umur merupakan faktor yang terpenting, mengingat hal tersebut mempengaruhi kekuatan fisik dan psikis seorang perawat dalam bekerja. Semakin tinggi umur perawat maka akan mengalami perubahan dan perkembangan kekuatan fisik, emosional, ilmu pengetahuan dan pengalaman kerja. Usia perawat, pengalaman kerja, jenjang karir, temuan studi ini menunjukkan perlunya menyesuaikan CPD atau kegiatan pembelajaran sesuai dengan kebutuhan kelompok usia atau generasi yang berbeda. Temuan dari penelitian lain menunjukan bahwa perawat yang lebih muda berada di sisi yang lebih dirugikan dan memiliki kesempatan yang lebih rendah untuk partisipasi CPD (Kivinen, 2012).

Kepuasan kerja perawat wanita secara keseluruhan lebih rendah dari pada pria di semua dimensi kecuali untuk kepuasan mereka dengan pekerjaan mereka. Namun, tidak ada perbedaan yang signifikan antara perawat wanita dan pria di semua dimensi kepuasan kerja mereka kecuali untuk kepuasan mereka dengan pekerjaan perawat khusus mereka (Akbari, Bagheri, Fathollahi, \& Darvish, 2020). Sebagian besar perawat sudah menikah. Dukungan keluarga dan rasa koherensi ditemukan menjadi prediktor yang signifikan untuk kualitas hidup yang tinggi di semua domain. Kebanyakan perawat menghabiskan lebih banyak waktu untuk bekerja dari pada kehidupan pribadi mereka (Rn, Mn, Rn, \& Rn, 2018). Perbedaan terhadap pengalaman bekerja perawat memungkinkan memiliki pengaruh proses penentuan siapa yang akan mengikuti pelatihan dan pengembangan kompetensi keperawatan. Situasi demikian tentu memberikan gambaran tentang tahapan pengembangan diri perawat dan pengelolaan SDM perawat rumah sakit. Pendidikan dapat mempengaruhi kemampuan (ability) seseorang terutama pada aspek pemahaman, sikap dan keterampilan terhadap pengembangan diri. Semakin lama seorang bekerja maka semakin memungkinkan dia untuk mendapatkan pengalaman dan jumlah pelatihan yang banyak dari rumah sakit.

Analisis karakteristik demografis dan pekerjaan terkait perawat mengungkapkan wawasan yang signifikan ke dalam angkatan kerja keperawatan saat ini. Pengetahuan bahwa CPD dapat meningkatkan keterampilan di tempat kerja dianggap sebagai fasilitator utama keikutsertaan CPD perawat dalam penelitian ini. Perawat dalam penelitian ini tampaknya secara langsung diketahui pentingnya CPD dalam karier mereka. Namun, meski perawat menyadari pentingnya CPD dalam meningkatkan kompetensi profesional mereka, tampaknya masih belum menyadari sepenuhnya tentang pentingnya CPD dalam mencapai visi pribadi mereka dalam jangka pendek maupun jangka panjang. American Nurses Association memberikan definisi yang mencakup tujuan pengembangan profesional keperawatan untuk mencakup tidak hanya tentang mempertahankan kompetensi dan meningkatkan praktik profesional tetapi juga dalam mendukung pencapaian tujuan karir perawat(Pool, Poell, \& Berings, 2015). Mendukung pencapaian tujuan karir perawat dalam hal mendapatkan dukungan pembiayaan, kebijakan dan pengembangan jenjang karir menjadi harapan yang penting bagi mereka. Misalnya dalam hal jenjang karir dimana beberapa perawat yang usianya tergolong dewasa (30-40 Tahun) masih ada yang berstatus sebagai perawat klinis level 1 dan 2. Hal ini menunjukan gambaran permasalahan pengembangan karir keperawatan dengan berbagai variasi dan kemajuan. Sejalan dengan itu, penelitian di Belanda(Brekelmans, Poell, Wijk, \& Brekelmans, 2013) dan Finlandia(Kivinen, 2012) mencatat variasi dalam persepsi dan sikap terhadap CPD dengan perawat yang lebih muda dan lebih tua. Para penulis menyimpulkan bahwa persepsi mengenai tujuan CPD bervariasi dengan usia dan perubahan sepanjang umur(Brekelmans et al., 2013). Peneliti di Kanada juga memperhatikan beberapa perbedaan usia dalam pengalaman karir, harapan, dan kebutuhan perawat. Perawat yang lebih muda, memiliki pengalaman yang lebih sedikit, dan pada tahap awal karir mereka termotivasi dan lebih bersemangat untuk memajukan karir mereka dan mencari peluang kerja yang mendukung pembelajaran mereka yang berkelanjutan, meningkatkan kompetensi dan membantu memfasilitasi transisi perubahan (Brekelmans et al., 2013) (Price \& Reichert, 2017).

Penelitian ini sebagian besar bersumber dari perawat yang bekerja di ruang rawat inap, dengan status perawat klinis tingkat 2 dan 3. Sebagain besar juga partisipan menduduki posisi sebagai staf perawat rumah sakit. Penelitian lain di India menyatakan bahwa penting juga untuk menyadari fakta bahwa dengan bertambahnya pengalaman bertahun-tahun, perawat melaporkan tingkat kompetensi klinis yang lebih rendah. Ini mungkin menyiratkan perlunya program CPD untuk menargetkan kompetensi 
klinis yang relevan untuk perawat berpengalaman. Bersamaan dengan kompetensi klinis, pengetahuan tentang peningkatan kualitas [QI], penilaian kinerja, audit klinis dan manajemen konflik diidentifikasi sebagai beberapa kompetensi manajerial utama untuk pengembangan diri perawat (Macaden et al., 2017). Beberapa perawat dalam survei ini dilaporkan mencapai posisi struktural dan jenjang klinis perawat begitu cepat melalui pendekatan dan rekomendasi manajer serta tingkat partisipasi CPD yang tinggi. Pengembangan diri mereka dinilai diatas rata-rata. Perawat dengan kualifikasi tambahan kegiatan informal dilaporkan lebih kompeten secara manajerial daripada mereka yang memiliki pengalaman secara formal, mungkin karena banyak varian dan jenis pelatihan dan pendidikan yang diikuti. Upaya untuk memperkuat kompetensi klinis dan manajerial melalui CPD harus diseimbangkan dengan cermat berdasarkan peran klinis perawat di unit kerja. Program CPD sangat penting untuk meningkatkan kualitas dan keamanan perawatan yang diberikan oleh perawat selain untuk meningkatkan kepuasan kerja dan moral staf (Macaden et al., 2017).

Perawat dalam survei ini juga dilaporkan bahwa mereka medapatkan dukungan kebijakan pengembangan diri melalui pengembangan karir, pendidikan dan pelatihan serta sarana yang memadai untuk mendukung perawat meningkatkan pengetahuan dan keterampilan. Tidak sedikit perawat dalam meningkatkan diri mendapatkan banyak hambatan terutama masalah pembiayaan. Hambatan menghadiri pelatihan CPD sebagian besar termasuk alasan pribadi seperti tanggung jawab rumah tangga, jarak, biaya dan alasan profesional seperti kurangnya informasi dan dukungan manajerial. Hambatan serupa untuk kehadiran CPD telah ditemukan di tempat lain; termasuk, kurangnya waktu dan keuangan, akses ke CPD (Tiwari, 2012), kesulitan menyeimbangkan pekerjaan, melanjutkan pendidikan, dan kehidupan rumah(Ross, Barr, \& Stevens, 2013). Oleh karena itu, untuk memaksimalkan partisipasi dalam CPD, perlu diciptakan lingkungan agar perawat dapat berpartisipasi secara interaktif dengan memperhatikan kebutuhan profesional, pribadi dan sosial perawat. Pendekatan ini ditanggung melalui bukti dan penelitian telah menunjukkan bahwa dukungan organisasi yang kuat, seperti waktu belajar yang dibayar, kepemimpinan yang kuat dan sikap positif terhadap CPD dari manajemen dan rekan kerja memfasilitasi pembelajaran yang efektif (CM Fahey,
2005).

Menarik juga untuk dicatat dari hasil survei, bahwa feedback telah memberikan banyak kemajuan untuk kontribusi pengetahuan dan keterampilan mereka. Kedudukan personal feedback dalam hal praktik klinis juga sangat berarti bagi mereka. Dukungan sejawat, mentor kerja dan supervisor sangat berarti. Penting bahwa ketika merencanakan pelatihan CPD, akan bermanfaat untuk melibatkan semua pemangku kepentingan terutama perawat staf dengan penekanan untuk mempromosikan hasil pasien yang berkualitas, pemikiran kritis, penalaran klinis dan penilaian ahli(CM Fahey, 2005).Agar program CPD efektif, program tersebut harus responsif terhadap kebutuhan profesional dan pribadi dan yang lebih penting mencerminkan prioritas kesehatan strategis rumah sakit.

Temuan dari survei ini telah membantu menetapkan kebutuhan pengembangan diri perawat baik jangka pendek maupun jangka panjang. Prioritas rencana pengembangan jangka pendekt CPD yang diidentifikasi dilaporkan kepada pemenuhan asuhan keperawatan dan target karir klinis dari level satu hingga level empat. Kebutuhan untuk mengembangkan kompetensi klinis mereka pada dasarnya sangat penting juga untuk mendorong layanan yang berkualitas. Penerapan pendekatan strategis organisasi akan memastikan penargetan yang lebih tepat dari pendidikan berkelanjutan yang langka dan sumber daya pengembangan profesional (Joyce, 2007).

Beberapa perawat memiliki rencanauntuk melanjutkan pendidikan yang lebih tinggi misalnya melanjutkan ke program magister dan spesialis perawat meskipun ada yang tidak memiliki rencana pengembangan jangka panjang. Penelitian lain menunjukan perawat tampaknya mengkonseptualisasikan pengembangan profesional berkelanjutan dalam tiga dimensi: tujuan, tingkat formalitas kegiatan pembelajaran, dan ruang lingkup pengembangan (Pool, Poell, \& Berings, 2015). Kebutuhan dan harapan yang diungkapkan untuk perawat di berbagai tahap karir. Perawat karir awal mengharapkan pelatihan dan pendidikan yang cukup untuk memfasilitasi transisi di tempat kerja, serta kesempatan pendidikan berkelanjutan sepanjang karir mereka untuk naik karir. Untuk perawat karir menengah hingga akhir, pentingnya pembelajaran seumur hidup dipahami dalam konteks mempertahankan kompetensi, memberikan perawatan pasien yang berkualitas dan meningkatkan 
peluang karir di masa depan. Pendidikan dan pelatihan terkait langsung dengan kepuasan karir perawat. Lingkungan kerja yang sehat diidentifikasi oleh perawat sebagai lingkungan yang berinvestasi dalam peluang pengembangan profesional berkelanjutan untuk memastikan pertumbuhan berkelanjutan dalam praktik mereka dan memberikan perawatan pasien berkualitas optimal. Pelatihan dan pendidikan muncul sebagai tema lintas sektor di semua tahap karier dan memiliki implikasi untuk perawatan pasien, serta retensi dan perekrutan (Price \& Reichert, 2017). Penelitian lain menunjukkan hubungan yang jelas antara pendidikan pembelajaran dan kegiatan pengembangan dan sikap kerja dan kinerja Investasi dalam pembelajaran dan pengembangan perawat berdampak positif pada perawatan pasien, perawat individu, dan organisasi perawatan kesehatan(Johnson, Hong, Groth, \& Parker, 2010). Di tingkat individu, faktor kunci yang muncul adalah kesadaran dan pemahaman tentang CPD, tuntutan yang bertentangan tepat waktu, ketersediaan dana, dan akses ke sumber daya CPD(Hemmington, 2000). Motivasi individu adalah salah satu faktor paling signifikan yang diidentifikasi sebagai kontribusi terhadap partisipasi dalam CPD. Jika perawat tidak termotivasi untuk mengubah perilakunya, tidak ada jumlah CPD yang efektif(Kiriaki, Olga, Christos, Aikaterini, \& Lambrini, 2020).

Pada level organisasi, peran CPD dipengaruhi oleh hubungannya dengan strategi organisasi, komitmen pengambil keputusan kunci, dan penyediaan infrastruktur internal untuk CPD. Tanpa dukungan dan dorongan dari atasannya, perawat akan mengalami kesulitan dalam pengembangan profesionalnya. Mayoritas perawat membutuhkan dukungan dan saran untuk CPD (Hemmington, 2000). Berbagai faktor lain juga mempengaruhi komitmen individu dan organisasi terhadap CPD dan kemampuan untuk melaksanakan $\mathrm{CPD}$, termasuk perencanaan pengembangan profesional, budaya pembelajaran, dan dinamika perubahan(Hemmington, 2000). Komponen kunci yaitu kerja tim dan semangat tim, sikap perawat itu sendiri, kemungkinan untuk berpartisipasi dalam program pelatihan, dan komunikasi yang efektif untuk merangsang CPD (Brekelmans et al., 2013). Faktor pendorong dan hambatan CPD dapat dipertimbangkan pada tiga tingkatan yang berbeda: individu, organisasi dan pada tingkat lingkungan bisnis. Di tingkat pekerja individu, masalah utama yang muncul adalah kesadaran dan pemahaman tentang CPD, tuntutan yang bertentangan tentang waktu, ketersediaan dana, dan akses ke sumber daya. Pada level organisasi, peran CPD dipengaruhi oleh hubungannya dengan strategi organisasi, komitmen pengambil keputusan kunci, dan penyediaan infrastruktur internal untuk CPD.

Kepemimpinan organisasi memegang peranan penting dalam mendukung kehadiran dalam melanjutkan pengembangan profesional sebagai investasi untuk masa depan (Coventry, Maslin-prothero, \& Smith, 2015). Wawasan ini dapat membantu rumah sakit untuk mengarahkan pendekatan pengembangan profesional yang berkelanjutan terhadap kebutuhan semua kelompok umur. Ini harus sangat relevan dalam menghadapi perubahan demografis saat ini dalam angkatan kerja perawat yang semakin meningkat. Perawat mencari bimbingan di tempat kerja mereka untuk memastikan, membangun dan mengembangkan pengetahuan praktis dan profesional mereka. Struktur hierarki, praktik budaya, dan hubungan pribadi di tempat kerja mempengaruhi aksesibilitas pengetahuan dan pengalaman. Pembelajaran di tempat kerja merupakan bagian penting dari pengembangan profesional saat pembelajaran sebagai proses mengubah pelajar dan lingkungan. Bidang keperawatan sangat beragam dan selalu berubah (Skår, 2010).

\section{KESIMPULAN}

Tingkat partisipasi yang tinggi terhadap program (CPD) mendukung jenjang karir dan profesional perawat. Rencana jangka pendek merupakan prioritas pemikiran perawat dalam meningkatkan (CPD) yaitu pemenuhan praktik asuhan keperawatan secara lengkap dan berkesinambungan. Rencana jangka panjang perawat yaitu melanjutkan program pendidikan pada jenjang lebih tinggi seperti pendidikan spesialisasi dan magister perawat. Kesadaran dan tingkat partisipasi (CPD) di dukung oleh aspek pembiayaan, feedback, kualitas kerja dan rencana pengembangan, kondisi kerja dan personal feedback.

\section{DAFTAR PUSTAKA}

Akbari, M., Bagheri, A., Fathollahi, A., \& Darvish, M. (2020). Job satisfaction among nurses in Iran : does gender. Journal of Multidisciplinary Healthcare, 13(71-78), 71-78.

Brekelmans, G., Poell, R. F., Wijk, K. Van, \& Brekelmans, G. (2013). Factors influencing continuing professional development A Delphi study among nursing experts. European Journal 
of Training and Development, 37(3), 313-325. https://doi.org/10.1108/03090591311312769

CM Fahey, J. M. (2005). Australian rural midwives : perspectives on continuing profesional development. The International Electronic Journal of Rural and Remote Helath Research, Education, Practice and Policy.

Coventry, T. H., Maslin-prothero, S. E., \& Smith, G. (2015). Organizational impact of nurse supply and workload on nurses continuing professional development opportunities : an integrative review. Journal of Advanced Nursing, 71(12), 2715-2727. https://doi.org/10.1111/jan.12724

Department of Health South Australian. (2014). Nursing and Midwifery Capability Department of Health South Australian.

Hariyati, R. T. S., Igarashi, K., Fujinami, Y., Susilaningsih, F. S., \& Prayenti. (2017). Correlation between Career Ladder, Continuing Professional Development and Nurse Satisfaction: A Case Study in Indonesia. Journal of Nursing Management, 10 (nursing career), 1-3.

Hemmington, N. (2000). Barriers and drivers to continuing professional development: The case of the hospitality industry. Continuing Professional Development, 3, 23-32.

Johnson, A., Hong, H., Groth, M., \& Parker, S. K. (2010). Learning and development: promoting nurses' performance and work attitudes. Journal of Advanced Nursing, 67(3), 609-620. https://doi. org/10.1111/j.1365-2648.2010.05487.x

Joyce, P. (2007). Continuing professional development : investment or expectation ? Journal of Nursing Management, 15, 626-633.

Kementrian Kesehatan RI. (2014). UU No.38 Tahun 2014 Tentang Keperawatan. Jakarta: Sekretariat Negara.

Kiriaki, T., Olga, Z., Christos, I., Aikaterini, F., \& Lambrini, K. (2020). Factors Affecting Nurses Lifelong Learning. Sanitas Magisterium, 1-9.

Kivinen, J. L. T. (2012). Continuing professional development in nursing: does age matter? Journal of Workplace Learning Continuing, 24(1), 34-47.

Macaden, L., Washington, M., Smith, A., Thooya, V., Selvam, S. P., George, N., \& Mony, P. K. (2017). Continuing Professional Development: Needs, Facilitators and Barriers of Registered Nurses in India in Rural and Remote Settings: Findings from a Cross Sectional Survey. Open Journal of Nursing, 271, 930-948. https://doi.org/10.4236/ ojn. 2017.78069

Muhadi. (2019). Laporan Hasil Penelitian: Analsisi Kebutuhan Pelatihan Perawat. Surabaya.

Pool, I. A., Poell, R. F., \& Berings, M. G. M. C. (2015). International Journal of Nursing Studies Strategies for continuing professional development among younger, middle-aged, and older nurses : A biographical approach. International Journal of Nursing Studies, 52(5), 939-950. https://doi. org/10.1016/j.ijnurstu.2015.02.004

Pool, I. A., Poell, R. F., Berings, M. G. M. C., \& Ten Cate, O. (2015). Strategies for continuing professional development among younger, middle-aged, and older nurses: A biographical approach. International Journal of Nursing Studies, 52(5), 939-950. https://doi.org/10.1016/j. ijnurstu.2015.02.004

Price, S., \& Reichert, C. (2017). administrative sciences The Importance of Continuing Professional Development to Career Satisfaction and Patient Care : Meeting the Needs of Novice to Mid- to Late-Career Nurses throughout Their Career Span. Administrative Sciences, 17(7), 4152. https://doi.org/10.3390/admsci7020017

Rn, Y. K., Mn, S. F. Y., Rn, S. M., \& Rn, M. S. N. (2018). Investigating nurses' quality of life and work- life balance statuses in Singapore. International Nursing Review, 1-9. https://doi. org/10.1111/inr.12457

Ross, K., Barr, J., \& Stevens, J. (2013). Mandatory continuing professional development requirements : what does this mean for Australian nurses. BMC Nursing, 12(9), 1472-6955. https:// doi.org/https://doi.org/10.1186/1472-6955-129.

Rumah Sakit Islam Surabaya. (2018). Laporan Seksi Diklat RSI Abmad Yani Surabaya. Surabaya.

Skår, R. (2010). How Nurses Experience Their Work as a Learning Environment. Vocations and Learning, 3, 1-18. https://doi.org/10.1007/s12186-0099026-5

Tiwari, R. (2012). Situational analysis of nursing education and work force in India. Nurs Outlook, (October 2017), 129-136. https://doi. org/10.1016/j.outlook.2012.07.012 